\title{
Dando tiempo a la actualidad. Querella de las viejas artes y las nuevas technés
}

\author{
Luis Puelles \\ Universidad de Málaga, España
}

\section{Resumen}

Se persigue la confrontación entre dos regímenes contemporáneos de "artisticidad", el correspondiente a las pragmáticas de estetización del mundo y aquel otro adscribible -asumiendo, desde luego, cuantas heterodoxias y rupturas convenga aceptar- al sistema moderno de las bellas artes. Este doble plano de lo artístico nos permitirá observar cómo nos hallamos en una época en la que los poderes de administración del mundo actúan mediante procedimientos de gestión de las imágenes mediáticas y telemáticas regidos por la absolutización de la inmediatez y la instantaneidad. Frente a los artistas-gestores de imágenes, estas páginas se aproximan a la rehabilitación hermenéutica de un arte (de auctores) que, en lúcida revisión de la modernidad, sea capaz de cargar con el tiempo para restituir a la experiencia humana el dramatismo y la nostalgia.

Palabras clave: arte contemporáneo, estetización, imagen, nostalgia, temporalidad.

Abstract
We will pursue the confrontation between two contemporary
regimes of "artisticness", corresponding to the pragmatic way of
aesthetization of the world and an other that can be ascribed to 
the modern system of the arts -assuming, of course, how many heterodoxies and ruptures convene to accept. This dual level of the artistic will let us observe how we are in a time in which the powers of administration of the world are acting through the management procedures of the media and telematic images governed by the absolutism of immediacy and instantaneity. Faced to the artists-managers of images, these pages approximate the hermeneutic rehabilitation of an art (of auctores) that, in lucid review of modernity, will be able to bear the time for restoring to the human experience the drama and the nostalgia .

Key words: Contemporary art, “Aestheticization”, Image, Nostalgia, Temporality.

- Cómo preguntarse por el arte en el que se comparte el tiempo en el que estamos -precisamente así: compartiéndolo- y al que de modo rutinario llamamos "arte contemporáneo"? Acaso corresponde al autor, para llegar a serlo, hacerse responsable (auctor significa productor, pero también responsable; esto es, es auctor quien asume responder por algo que toma como propio y no sólo a algo puesto por otro), preguntar-se por las posibilidades hermenéuticas de habitabilidad del presente que nos es (en) común, proponiendo éticamente y artísticamente la desconfianza respecto a lo dado por la actualidad, con la que el artista moderno -Durero, Goya, Baudelaire, Daumier, Duchamp o Warhol- entabla relaciones dramáticas, reticentes, recelosas, incrédulas e irónicas, hasta el punto de ganar para su mirada aislada el afuera de la actualidad.

Las reflexiones que aquí se presentan persiguen la diferenciación entre dos regímenes de "artisticidad", existentes en nuestra contemporaneidad. Diferenciación con la que se relacionan respectivamente de maneras divergentes y eventualmente confrontadas. El primero de estos dominios podría prestarse a ser nombrado con la fórmula recurrente de "arte contemporáneo", la cual se nos hace 
reconocible mediante la adscripción -con todas las heterodoxias y cuestionamientos emancipatorios que queramos concederle- al linaje de las bellas artes, instituidas como tales por determinados saberes teóricos y por ciertas prácticas de identificación y confinamiento que comenzaron a partir de las últimas décadas del siglo XVII y siguieron a lo largo del XVIII, con las decisivas formulaciones de Lessing y Kant. Este régimen designa un espacio bien organizado entre historiadores del arte, museos y publicaciones, galerías y comisarios, coleccionistas y público con frecuencia especializado o cercano a este "mundo". En todo caso, se trata de un campo de "artisticidad" designable en términos situacionales (esto es: aceptaríamos llamar arte contemporáneo al que es expuesto en "museos o centros de arte contemporáneo") o relacionales (supondríamos que es arte contemporáneo el realizado por artistas a los que la crítica y los historiadores del arte adscriben a "movimientos" artísticos de los últimos cincuenta años).

Ahora bien, con independencia de este arte de las bellas artes sería posible postular para nuestro tiempo unas praxis productivas rigurosamente "integradas" en el decurso de la actualidad y capaces (con la destreza propia de las technés) de satisfacer con eficacia las exigencias pragmáticas que se le reclaman por parte de los agentes fácticos de administración del mundo en el que estamos (o más precisamente: del mundo que se nos $d a$ ). Este segundo régimen de las artes en la contemporaneidad, a las que me referiré aquí llamándolas "nuevas technés", avanzan sin ser suficientemente consignadas por las disciplinas teóricas concernientes al hecho artístico, quedando por lo tanto desapercibidas. No están en el museo, ni en los catálogos de exposiciones, ni en las ferias y revistas de "arte contemporáneo"; actúan -sabiendo hacerlo: insisto en que no es otra la definición de techné- al servicio de los poderes de administración del mundo. Son artes orgánicas o integradas: la publicidad, los medios y las tecnologías de la comunicación, el marketing, las 
industrias del entretenimiento, etc., requieren de una mano de obra experta en suscitación retórica de efectos de consumo, fascinación y credulidad. Los dueños de la administración del mundo emplean a gestores de la seducción, el deseo y el consumo (material, pero también simbólico e ideológico). Estos empleados, aplicados con frecuencia de forma anónima - sin ser autores- en la gestión de la estetización del mundo, son los "nuevos artistas" o, mejor, los técnicos de la actualidad. El régimen anterior al que me he referido, el de las viejas bellas artes y sus herederos contemporáneos (más o menos díscolos, pero en todo caso internados en el museo), correspondería, en confrontación con ésta, a los autores (auctores) de la contemporaneidad. Esta diferenciación, todavía no mucho más que terminológica, será desarrollada con mayor detalle en la última parte de estas páginas.

Antes de ello, en un primero momento he creído conveniente dar alguna explicación de ciertas implicaciones contenidas en la expresión "estetización del mundo". De este modo, comenzaremos nuestra andadura con una propuesta de diagnóstico para nuestra época: el de la estetización radical o esencial del mundo, afirmándose con esto que éste queda ontológicamente disuelto en la evanescencia de sus modos (transportables, comercializables y particularmente transformados en imágenes).

En un segundo momento sugeriré tres secuencias o paradigmas "históricos" de relación con el mundo, definidos respectivamente por las exigencias de representación, de realización y por la que nos es propia: la exigencia omnímoda de la gestión. Traer el mundo a la versatilidad de su gestión -en esencia "comercial"- requiere someterlo al estatuto versátil de las imágenes. La ontología pragmática de la imagen en la actualidad será analizada en esta parte intermedia.

Por último, entraré en la confrontación entre autores y artistas buscando una diferencia decisiva que aquí tiene la pretensión de 
no ser más que una propuesta para su discusión: son los autores herederos de las viejas bellas artes los que cargan con la temporalidad (es afrontando éticamente esta responsabilidad como se hacen auctores) y, al contrario, son los nuevos artistas de la gestión los que emplean sus fuerzas en transformar la temporalidad dramática en un instante intenso para su consumo raudo y ligero. Al llegar a este punto, propondré la gnosis de la nostalgia como condición arqueológica constitutiva del "arte contemporáneo" creado por los autores. Avancemos ya en la elaboración de estas tres partes.

\section{I}

Iniciemos nuestro recorrido reparando en una constatación previa, quizá algo inquietante, la cual dice que más allá de cómo debamos conducirnos en la elaboración de una teoría estética del presente, éste posee, con primacía sobre ninguna otra estimación, un estatuto ontológico fundamentalmente estético. Es propio de la contemporaneidad estar determinada estéticamente de modo esencial y no accidental o superficial. Esto es lo que se indica en la fórmula heideggeriana por la cual habitamos "la época de la imagen del mundo", pero no parece inoportuno abundar en que, cuando es así, cuando el presente es predominantemente reconocible en sus cualidades estéticas, lo relevante no es aquello que prime lo estético en sus derivaciones hacia la estetización, sino que el mundo no está determinado en términos sustantivos y perdurables, más bien se presenta resuelto y disuelto para su administración en la variedad de sus modos (variedad requerida por las leyes mercantiles del consumo: variedad inabarcable, irreductible, hasta conseguir hacer desaparecer el acceso a lo básico-necesario, lo cual, por cierto, viene siendo reclamado por "estrategias alternativas" de recuperación y mantenimiento de lo simple-ejemplos de esto son el ecologismo o el consumo responsable); para la administración de los modos y, 
con ello, para la suscitación del efecto de inmediatez, consistente en la ilusión de que todo está a la mano, ahi ya para su adquisición, su acceso, su posesión, su manejo por y para todos. Cercanía y celeridad son dos condiciones de la ideología por la que el mundo queda sometido a la comercialización global de su consumo; cercanía y celeridad son los dos mandamientos que deberán cumplir con obediencia las nuevas technés. Creo que podrá ser suficiente con lo expresado en estas últimas líneas para convenir en la relevancia "política" de la gestión estético-pragmática del mundo que nos queda. Tal y como Maffesoli, Rancière y otros han observado recientemente lo han hecho Lipovetsky y Serroy en La estetización del mundo-, pensar el presente exige pensarlo en sus cualidades estéticas; la tarea de una ontología estética que se proponga dar razón de lo real no puede eludir ser una ontología política interesada por el análisis de los agentes y procesos de transformación de lo real y de la subjetividad en términos de cualidades y experiencias estéticas.

Llegamos así a la constitución de un estado de realidad que permite con toda propiedad que lo definamos como un estado de estetización de la vida cotidiana, con el que se asiste a un vuelco del sistema tradicional de las bellas artes en beneficio de una expansión indiferenciada de las industrias estéticas. Michel Maffesoli ha definido con claridad el nuevo concepto de estetización generalizada o difusa:

se trata de dar al término estética su sentido pleno, y no reducirlo a lo que tiene relación con las obras de la cultura o sus interpretaciones. Mostraré que la estética está dispersa en el conjunto de la existencia. Ha contaminado la política, la vida de la empresa, la comunicación, la publicidad, el consumo y desde luego la vida cotidiana. Quizás, para hablar de una estetización galopante, del ambiente específico que ella segrega, hará falta retomar la expresión alemana de Gesamtkunstwerk, obra de arte total. Un arte que 
va a observarse en la superación del funcionalismo arquitectónico o en el del objeto usual. Desde el ámbito de la vida al reclamo del diseńo, todo parece devenir obra de creación, todo parece comprenderse como la expresión de una experiencia estética primera. Desde ahora, el arte no podrá ser reducido a la producción artística, esto es, la de los artistas, sino que deviene un hecho existencial $\left(1990: 12^{) .1}\right.$

Si bien es relevante atender a los cambios implicados en esta pandemia esteticista (Yves Michaud ha utilizado la expresión éther esthétique: una especie de metástasis que todo lo convierte en seducción estética, en voluntad de estilización, en prioridad de gustar), necesaria al fin para hacer del mundo un objeto atractivo que promueva su consumo, me parece que lo más importante habría que buscarlo en cómo se han transformado las condiciones de la experiencia humana a partir de estos cambios. La primacía de la experiencia estética sobre la experiencia artística ha logrado imponerse en términos totalitarios (por lo tanto contra-éticos o supresores de la diferencia entre las "esferas" de la subjetividad): la antropología del sujeto de nuestro tiempo debe partir de la evidencia de que todo en él pasa por la absolutización de la dimensión

${ }^{1}$ Por su parte, Baudrillard se ha expresado en este mismo sentido: "El arte se ha realizado hoy en todas partes. Está en los museos, en las galerías, pero también en la basura, en los muros, en las calles, en la banalidad de todas las cosas hoy sacralizadas sin ninguna forma de proceso. La estetización del mundo es total. Así nos enfrentamos a una materialización burocrática de lo social, a una materialización tecnológica de lo sexual, a una materialización mediatizada y publicitaria de lo político, nos enfrentamos a una materialización semiótica del arte" (2006: 11). En La transparencia del mal, escribe este autor: "Si en el fondo el arte sólo era una utopía, es decir, algo que escapa a cualquier realización, hoy esta utopía se ha realizado plenamente: a través de los media, la informática, el vídeo, todo el mundo se ha vuelto potencialmente creativo [... [ Toda la maquinaria industrial del mundo se ha visto estetizada, toda la insignificancia del mundo se ha visto transfigurada por la estética” (1994: 22). 
estética. Nos encontramos con un mundo y unos sujetos esencialmente modales, estetizados, reconocibles a través de sus accidentes y atributos, a través de sus gustos y de su estilo; un sujeto fuertemente superficial y éticamente indiferente. No obstante, esta antropología modal no afecta sólo a la apariencia con la que nos presentamos ante los demás, sino que tiene su mayor definición en el predominio de la sensibilidad sobre cualquier otra esfera de lo humano. "Sentir lo media todo" (Perniola, 2002: 29). La realidad deberá satisfacer ahora las exigencias de sensibilidad y sentimentalidad intensas, en las cuales aquella queda asimilada.

Según creo, es justamente el campo de pruebas de la experiencia humana el que centra cuantas disquisiciones quisiéramos hacer a propósito de la dimensión sociopolítica de la cualificación modal, superficial y aspectual, tanto del mundo mismo como de nuestras vivencias ("actuales") en él. En este punto se hace difícil no recordar ciertas líneas de Georg Simmel, quien en "Las grandes urbes y la vida del espíritu” (1903) escribía:

El fundamento psicológico sobre el que se alza el tipo de individualidades urbanitas es el acrecentamiento de la vida nerviosa, que tiene su origen en el rápido e ininterrumpido intercambio de impresiones internas y externas. El hombre es un ser de diferencias, esto es, su consciencia es estimulada por la diferencia entre la impresión del momento y la impresión precedente. Las impresiones persistentes, la insignificancia de sus diferencias, las regularidades habituales de su transcurso y de sus oposiciones consumen, por así decirlo, menos consciencia que la rápida aglomeración de imágenes cambiantes, menos que el brusco distanciamiento en cuyo interior lo que se abarca con la mirada es la imprevisibilidad de impresiones que se imponen (2001: 376).

Estas palabras del sociólogo alemán nos sitúan ante un problema clave de la contemporaneidad: la supresión progresiva de la $d u$ ración -es significativo que en esos mismos años iniciales del siglo 
XX también Bergson se interese persistentemente por su estatutocomo exigencia para la constitución de la conciencia, de las actitudes en las que su subjetividad humana se gana a sí misma, por la imposición de una experiencia aisthesica más pática y reactiva que contemplativa y reflexiva, una experiencia apresurada, afirmada principalmente en su solo valor de novedad, que apenas permite el arraigo de la conciencia. Una experiencia instantánea, "performada" (excitada y dirigida) desde instancias externas al sujeto paciente. Es decir, tomando lo más relevante de la cita de Simmel, una experiencia en la que el sujeto acaba por quedar sensorialmente saturado, abotargado de "impacto" somático. Cabría suponer que este sujeto capturado por la experiencia de las grandes urbes - pero que, en todo caso, no está lejos de lo dictado para él por Wagner: ser tomado por todos sus sentidos-acabará por responder a la cosificación diagnosticada por Horkheimer y Adorno en su Dialéctica de la Ilustración; sin embargo, no hay que alejarnos demasiado y hay que retomar nuestro asunto.

Aproximadamente veinticinco años después de la publicación de este artículo de Simmel, Paul Valéry nos regalaba otro de los grandes documentos de la teoría estética del siglo XX: su escrito sobre "Leonardo y los filósofos" (1929), del que no reprimo reproducir aquí un fragmento deslumbrante:

Por otra parte, ¿en qué ocasión se puede precisar el designio de “crear una Estética”? ¿Una ciencia de lo Bello?... ¿Es que los modernos todavía usan esta palabra? Yo creo que sólo la usan a la ligera... O bien sueñan con el pasado... La Belleza es una especie de muerte. La novedad, la intensidad, la extrańeza y, en una palabra, todos los valores de choque, la han suplantado. La excitación en estado bruto es la dueńa soberana de las almas recientes; y las obras tienen actualmente por función arrancarnos al estado contemplativo, a la felicidad estacionaria cuya imagen, tiempo atrás, estaba íntimamente unida a la idea general de lo Bello. Las obras están 
cada vez más atravesadas por los modos más inestables e inmediatos de la vida psíquica y sensitiva, lo inconsciente, lo irracional, lo instantáneo, que son -y sus nombres lo proclaman- privaciones o negaciones de las formas voluntarias y sostenidas de la acción mental, se ven sustituidos por los modelos esperados por el espiritu (Valéry, 1987: 111-113).

Hagamos recuento de qué tenemos en nuestro fardo después de leer a estos dos teóricos de la modernidad: en el caso de Simmel, diagnóstico de acrecentamiento de la potencia de impresiónexcitación de la experiencia aisthesica en los espacios característicamente modernos (urbanos); en el caso de Valéry, la asociación de la belleza con una cierta concepción de la temporalidad, propia de la contemplación, próxima a un tiempo largo... como detenido. En contraste con una concepción estética de raigambre clásica, en la que la belleza nos recoge en el tiempo de la contemplación, Valéry testimonia la irrupción de unos valores de choque aliados del impacto, la novedad y la instantaneidad; medios por los que la experiencia humana (más allá de los confinamientos atribuidos a la "experiencia estética" en la modernidad) queda dominada en nuestros sociedades postindustriales (ultra-sintéticas) por dos registros del efecto sobre la sensibilidad: lo intenso, dirigido a la suscitación del efecto ilusionístico de realidad a través de sus simulacros (esto es, cuanto se designa en la categoría ontológica de lo hiperreal), y lo kitsch, lo falso en su efecto seductor como marca de época y que constituye nuestros sentimientos y emociones, nuestras vicencias y elecciones estéticas. Dos categorías capaces de desenvolverse en el tiempo -sin conciencia- de la instantaneidad.

Desearía alcanzar el tiempo que nos es actual proponiendo una genealogía en tres secuencias históricas de la modernidad occidental, 
cada una de ellas regida por un paradigma específico de relación "humano-civilizatoria" con el mundo: el paradigma de representación, al que seguirían el de realización y, ya en nuestro tiempo inmediato, el de gestión. Elaboremos este esquema con algún detenimiento. Para orientarnos, casi bastaría con entender que hacia mediados del siglo XIX se produjo un cambio decisivo, por el que transitamos desde la episteme teoricista de la representación hacia las praxis e ingenierías de la realización. Así, nos desplazaríamos ideológicamente desde la representación cognoscitiva de la realidad a la realización en presencia del mundo. Esto también encuentra su formulación en el espacio definido por las artes, puesto que acontece un arte industrial, orientado y cumplido en su uso eficaz, que consigue sustraerse del credo kantiano de un arte estético (en contraposición a un arte, el de las bellas artes, creado para su contemplación; erigido mediante el privilegio de sus valores formales y la exclusión de la utilidad y la servicialidad práctica o ideológica).

El siglo XIX conoce en todo su vigor la aparición de las technés de la realización; por lo que podríamos pensar en la enorme relevancia que cobran las ingenierías transformadoras de los entornos naturales y urbanos. La contemplación del mundo se doblega ante las exigencias pragmáticas que persiguen su posesión fáctica. El siglo de Comte y Verne, de Owen y Fourier, desarrolla un modo de afrontar la realidad que no es ya el que compone su representación, sino el que la toma como materia versátil para la realización revolucionaria de lo posible humano. ${ }^{2}$

Tras estos dos umbrales de relación con el mundo (el determinado por el paradigma teoricista de la representación y el definido, entre los siglos XIX y XX, por la potencia de realización)

${ }^{2}$ En este sentido parece obligado recordar el libro clásico de Ernst Jünger sobre El trabajador. Dominio y figura (1932). Por su parte, Félix Duque ha analizado la instauración civilizatoria de la ingeniería en Filosofía de la técnica de la naturaleza (1986). 
cabe postular un tercer momento, el específico de nuestra contemporaniedad, identificable por lo que podríamos llamar las praxistecnológicas de la gestión de/en un espacio absoluto de circulación (sin esperar: sin duración) en el que todo sea susceptible de ser absorbido por estas pragmáticas de fuerte impronta telemática. La consecuencia directa de este nuevo paradigma es que el mundo se presta a ser poseído mediante su reducción a imágenes susceptibles de tratamiento digital para su administración y comercio. El artista de nuestro tiempo es el gestor de la postproducción de imágenes. Esta reducción disolutoria del mundo en sus imágenes administrables implica además la imposición tecno-lógica de la espectacularización. Dediquemos algunas líneas a estas dos circunstancias de la gestión del mundo en la época actual.

Respecto a la nueva ontología de la imagen, ésta debe rendirse a su plena disponibilidad. Propondré a continuación tres propiedades -o virtudes- de la imagen mediática y telemática, las cuales propician su trato pragmático por los poderes de mercantilización y desmaterialización del mundo: la primera sería la de su heteronomía. Lo conocido como "historia del arte moderno" se rige en torno a unas condiciones de posibilidad entre las que destaca, con especial relevancia para la definición de las artes bellas, la noción de autonomía, principio y postulado por el que se facilita la definición de un arte dotado de la capacidad de sólo rendir cuentas acerca de sí mismo y desde criterios estrictamente estéticos. Mientras que la ontología moderna de la obra de arte se sostenía en el primado de su autonomía (soberanía, suficiencia, autogénesis) y, en fin, en un cierto postulado de reflexión incluyente, la ontología de la imagen en sus pragmáticas actuales radica más bien en la condición de su exogénesis, de su estar saliéndose de sí, excluyéndose de su identidad. Pertenece a la "imagen" (religiosa, pero también publicitaria o periodística: imágenes y no obras artísticas) su carácter extático: su 
modo de ser es estando fuera de sí. Extática y centrífuga, la imagen carece de soberanía de sí.

Un segundo atributo que le es propio es el de su versatilidad. La imagen es susceptible -intrínsecamente-de manipulación: es pura forma, que puede transformarse, y localización, que puede desplazarse. Pura apariencia y puro tránsito dispuestos a "dejarse hacer". El poder superior de la imagen es su versatilidad, su flexibilidad. Es irrompible porque es capaz de admitir todo cambio posible sin la menor resistencia. Su paradigma, después de haberlo sido el collage, es la imagen de naturaleza digital. Lo virtual-digital actúa en la ilusión de supresión de la resistencia de la realidad. La imagen excluye al objeto (que publicita, del que informa, al que reverencia) porque éste no permite que se le entienda sólo visualmente. La imagen actual, por su insuficiencia, es inacabable: siempre podría ser intervenida un poco más. Es un sin fin, y por esto debe ser definida sin obviar su estatuto -deleuziano- de provisionalidad.

El tercer atributo que nos ocupa es el de la reproductibilidad (tan bien expresada en la omnipresencia de la "fotografiabilidad"). Lo fotografiable es la captura de la apariencia para su transmisión; lo que del objeto permite no sólo su traslado, sino la multiplicación de éste: su transmisión y exposición múltiple y simultánea. Para que un objeto -o sea, el mundo- pueda ser prolíficamente multiplicado y consumido, objeto así de transacción, debe ser objeto de traslación, de transporte, de transmisión, realizado como imagen -fotografiable- y convertido en apariencia. La ecuación no nos extraña: lo máximamente visible alcanzará a ser máximamente consumido. Como es sabido, las empresas dedican gran parte de sus esfuerzos a "ganar visibilidad". Una imagen es un objeto cuyo atributo principal es el de entrar en absoluta circulación (sin aura, sin restos, sin rastros); eso es la imagen digital: objeto en circulación; objeto en tránsito ubicuo. 
En lo relativo al campo del "arte contemporáneo", en la era de la estetización la última tentación de las bellas artes tiene la forma de un retorno a los dictados del siglo XVIII, cuando sólo se le permitía ser bella y vana: me refiero a la tentación actual de rendirse al comercio de la fotogenia. El arte contemporáneo se ha prestado sin demasiados escrúpulos a la exigencia mediática de ser arte fotografiable, susceptible de reproducción fotográfica y, por tanto, de difusión visual masiva y mediática, hasta definirse como mercancía espectacular. Hay que hacer algo impactante, dice el artista en promoción de sí, hay que hacer algo que funcione, que pegue, que rompa, que tenga fuerza visual; para esto, el artista se deja tomar por los nuevos instrumentos y se aleja de la conformación de su punto de vista hermenéutico.

De acuerdo con la gestión del mundo en sus imágenes, se asiste a la expansión de la espectacularidad, cuya lógica acaparadora no es otra que la hacerse presencia impositiva ocupando la totalidad del espacio perceptible. Esta espectacurización se acompaña de la pérdida de lo infinito, por la imposición de lo dado ocupando la superficie, y de la hipertrofia de la frontalidad perceptual.

El artista-gestor de las imágenes -como el periodista hace con "lo actual" - no puede entrar en profundidades: no se trata de conocer, sino de operar con inmediatez y eficacia. Toma la realidad superficialmente, en sus modos sensibles, para dirigir su voluntad de poder a la ampliación de las posibilidades de manejabilidad de la actualidad. Para esto es lo que debe hacerse con un determinado tipo de poder, el principal, consistente en ocupar el horizonte de visibilidad, puesto que se trata de gestionar poner a ver. Desde estos presupuestos, hacer imágenes (actividad artística todavía moderna) debe entenderse ahora como poner imágenes. Por lo anterior, la figura revolucionaria del productor ha quedado eclipsada por la 
del gestor-distribuidor ${ }^{3}$ el cual, en tanto que "pone a ver", programa los regímenes temporales de aparición, de promoción y extinción de lo visible en la forma del acontecimiento (objeto visual de la actualidad en sus tiempos de aparición y desaparición). No hay otro poder superior a éste y, por eso, no hay ningún poder que no necesite negociar con los gestores mediáticos.

\section{III}

El artista-auctor desautoriza la actualidad -lo dado por actualidadtomándola desde una contemporaneidad nostálgica o desde una distancia "histórica": yéndose al pasado para, con potencia crítica, hacer aparecer el presente negado por la actualidad; es en el presente y no en la actualidad donde pueden crearse posibilidades abiertas al futuro. El artista transformado en auctor adopta la memoria del pasado compartido; toma perspectiva acudiendo al pasado común. El auctor avanza a través de la conciencia nostálgica (no es otro su saber) y desdoblada entre el pasado y la actualidad, procurando la conversión de ésta en presente hacia el futuro. Esta conciencia nostálgica es la del artista de las bellas artes: la nostalgia constituye al arte moderno. La responsabilidad del auctor no es otra que la de darse a cargar con la conciencia del tiempo. El arte moderno no sabe más que representarse el tiempo y dárselo como carga; esta carga, hecha con el tiempo, es el sentido humano posible y prometeico.

Si las nuevas technés (oficios e industrias de la estetización global del mundo) se deslizan por la superficie de la actualidad, los últimos hijos de las viejas bellas artes (aquellos que producen un arte bien específico al que hemos dado en llamar "arte contemporáneo") quizá consigan mantenerse en una adorniana resistencia

${ }^{3}$ En "Redefinición de las prácticas artísticas (siglo 21)", José Luis Brea detectó con prontitud esta nueva figuración del artista (vid. El tercer umbral. Estatuto de las prácticas artísticas en la era del capitalismo cultural, 2004). 
en la medida en que conserven políticamente -en un uso crítico de la historia- una ética estética atenta a los restos de realidad y en la medida en que concedan una actitud asimilatoria de los componentes culturales de los símbolos de la pietà en su sentido más laico: una atención a lo inolvidable que desaparece, que es como el arte se funda en la nostalgia y, con ella, en la representación simbólica. Habría así una memoria -la que el arte moderno es- de los restos de realidad. Es fácil advertir hasta qué punto los artistas de la contemporaneidad se dan al recuerdo o al mantenimiento de los residuos de realidad, de lo que de ella pervive en los márgenes del espectáculo (ver Duque, 2002: 77ss).

La resistencia necesaria a la clausura de lo posible habría de dotarse de los recursos éticos, poieticos y hermenéuticos contenidos en la restitución de la temporalidad dramática. Por ahí emerge lo principal del arte moderno: la creación de variadas modalidades de la experiencia de temporalidad; entre ellas, la creación de los medios para la conversación entre las formas del pasado (críticas y políticas), la experiencia del presente como experiencia excepcional y la previsión del futuro como horizonte de lo posible creíble. Quizá de esta forma valdría indagar en la exigencia de desautorizar la actualidad añadiéndole tiempo humano: memoria, duración y proyecto.

En la exigencia ética de tomar posiciones (de auctor) ante la actualidad, atentos a ella, despiertos a ella, se hace preciso que el arte contemporáneo adopte para sí dos operaciones implicadas en este hacer frente a la actualidad: mirándola desde fuera (en un cierto movimiento de auto-extrańamiento respecto de la actualidad) y mirándola por/desde detrás (pudiendo así plantar cara a la actualidad sin quedar cegados por el espectáculo): frente a la actualidad, sin quedar inmerso en ella, ganando el espacio crítico -pero también nostálgico- de la distancia. 
Mirar desde fuera la actualidad -siendo de este modo como se pertenece a ella-significa abrir huecos en la pantalla plana y plenamente llena de la actualidad para, con distancia, entrever el tiempo del presente. Hay que traer en este punto el nombre de Baudelaire, para quien la tarea moderna consistiría en "extraer lo eterno de lo transitorio". Extraer, pero... ¿qué significa aquí "extraer"?

En una carta dirigida a Benjamin escrita por Adorno, desde la distancia algo nostálgica de Nueva York en la que recordando las conversaciones de los dos en Königstein, el alemán escribe: "dijiste que cada una de las ideas de los Pasajes debería ser arrancada de una región dominada por la locura". Entrever, extraer, arrancar: El arte y la filosofía se "posicionan" en la elección de una perspectiva (Panofsky, en su estudio clásico sobre la perspectiva como forma simbólica habla de ésta en una doble acepción: "ver a través de" supone también "ver con claridad"). Arte y filosofía saben -la perspectiva es una gnosis- abrir huecos en la pantalla frontal de la actualidad para atender a las preguntas de ¿̇cómo es presente el estado de lo presente en la actualidad? Y, ¿cómo pervive el presente, y a qué se destina, en nuestro estado de actualidad?

Pero, ¿¿ómo tomar la actualidad en perspectiva? ¿Cómo hacerse (con) un punto de vista propio que nos dé la experiencia del presente? ¿Dónde "ponerse"? La contemporaneidad del arte y la filosofía consistiría en situarse en una cierta disonancia, o desencaje, o desajuste; es decir, una cierta "inadaptación" con la actualidad (pero también una cierta "heterocronía"). Esto con el fin de poder evitar que el punto de vista coincida con el objeto de la actualidad (pues se escapa por la perspectiva "historicista" de la tiranía de la actualidad).

Sin embargo, arte y filosofía no sólo miran por detrás, sino que, para evitar ser deslumbrados por el espectáculo ("fantasmagórico" y espectral) de la actualidad, deben tomar sus posiciones desde detrás. La actualidad -la hiperrealidad- no tiene dentro, ni 
fundamento, pero sí tiene detrás, en tanto que es puro anverso, pura frontalidad: espectáculo dedicado a la expulsión del drama del tiempo y de la conciencia nostálgica. Desde detrás puede verse cómo se produce la falsificación del presente (de la experiencia del presente) por el impacto de la actualidad in-mediata.

El autor no teme, más bien prefiere, "quedarse atrás", haciendo suyo un estar sosteniendo y sosteniéndose en un tiempo que es el del pasado; como un quedarse atrás que nos abre alguna perspectiva - y expectativa- por la que convertir la actualidad en el tiempo del presente, por la que devolver el tiempo al presente. Ésta es la tarea del arte -y la filosofía- al que llamamos "contemporáneo". Mirar desde detrás es mirar desde el uso crítico del pasado humano, del pasado histórico (ese tercer modo de concepción de la historia que Nietzsche analiza con perspicacia en la segunda Consideración Intempestiva, después de dirigir sus críticas a los modelos monumental y documental). Tomar perspectiva desde detrás es, según lo entiendo, mirar desde el pasado cuanto de presente se espacializa en la actualidad, buscar el presente humano en la ocasionalidad del ahora. Porque la actualidad no es una noción temporal, sino una instancia sociopolítica para la administración del estado de hiperrealidad (sin pasado, sin vejez, sin tragedia).

Desde detrás, se carga con los restos de tiempo presente que la actualidad arroja y/o desecha y se rehabilita con nostalgia un detrás (un fondo de escenario) que haga visible la transparencia en la que se oculta la actualidad: que la dote de algún sentido, que la descubra en sus oscuridades. Sólo mirando desde detrás se hace posible poner un fondo al escenario: dar fondo a la actualidad para descubrir en ella -entresacar de la marabunta que colapsa la superficie- el carácter de presente; convirtiendo -a fuerza de mirar con tiempo, distancia y desde- por detrás el tumulto de la actualidad (del estado de hiperrealidad), o devolviendo, la temporalidad a lo presente en la actualidad. "Todo futuro determinado por el pro- 
yecto moderno sólo puede convertirse en realidad si tiende hacia el pasado. Ahí reside el aparente misterio del origen común de la conciencia histórica 'progresiva' y la museificación del pasado. La necesidad de encerrar y conservar el pasado en museos surge cuando se adquiere una idea general de Progreso" (Marramao, 2009: 89).

Arte y filosofía se encuentran conteniendo el tiempo (la génesis de lo que llamamos, con Gadamer, la tradición como exigencia del horizonte hermenéutico; cierta "transmisión" - no es otra la labor de Hermes- desde el pasado al presente y hacia el porvenir). El artista y el filósofo comparten la identidad que Nietzsche confería al "hombre histórico" en la ya referida segunda Consideración Intempestiva. Es así como aparece la conciencia moderna: comprendiendo el presente desde el pasado y hacia el futuro. Extrañándonos de la actualidad podremos seguir mirando hasta poder abrirnos un porvenir. Algo que nos descubra cómo somos y qué nos queda. El arte y la filosofía en la contemporaneidad -no sin más en la actualidad- del siglo XXI habrían de ser laboratorios nostálgicos, dramáticos, de lo posible humano.

\section{Bibliografía}

Baudrillard, Jean, 1994, La transparencia del mal, J. Jordá (trad.), Barcelona, Anagrama.

, 2006, El complot del arte. Ilusión y desilusión estéticas, Ma J. Domecq (trad.), Buenos Aires, Amorrortu.

Brea, José Luis, 2004, El tercer umbral. Estatuto de las prácticas artísticas en la era del capitalismo cultural,Murcia, Cendeac.

Duque, Félix, 1986, Filosofía de la técnica de la naturaleza, Madrid, Tecnos. 
Jünger, Ernst, 2003, El trabajador. Dominio y figura, A. Sánchez Pascual (trad.), Barcelona, Tusquets.

Maffesoli, Michel, 1990, Au creux des apparences. Pour une éthique de l'esthétique, París, Plon.

Marramao, Giacomo, 2009, Minima temporalia. Tiempo, espacio, experiencia, H. Aguilà Ruzola (trad.), Barcelona, Gedisa.

Michaud, Yves, 2005, L 'Art à l'état gazeux. Essai sur le triomphe de l'esthétique, París, Hachette.

Perniola, Mario, 2008, Del sentir, C. Palma (trad.), Valencia, PreTextos.

Schaeffer, Jean-Marie, 2005, Adiós a la estética, J. Hernández Iglesias (trad.), Madrid, Antonio Machado Libros.

Valéry, Paul, 1987, Escritos sobre Leonardo da Vinci, E. Castejón y R. Conte (trad.), Madrid, Visor.

Recibido:31 de junio de 2015 Aceptado:14 de octubre 2015 